\title{
Magnetic hysteresis up to 80 kelvin in a dysprosium metallocene single-molecule magnet
}

\author{
Fu-Sheng Guo, ${ }^{1}$ Benjamin M. Day, ${ }^{1,2}$ Yan-Cong Chen, ${ }^{3}$ Ming-Liang Tong ${ }^{3}$, Akseli Mansikkamäki ${ }^{4}$, \\ Richard A. Layfield ${ }^{1 *}$ \\ 1Department of Chemistry, School of Life Sciences, University of Sussex, Falmer BN1 9QJ, UK. 2School of Chemistry, The University of Manchester, Oxford Road, \\ Manchester M13 9PL, UK. 'Key Laboratory of Bioinorganic and Synthetic Chemistry of the Ministry of Education, School of Chemistry, Sun-Yat Sen University, Guangzhou \\ 510275, People's Republic of China. ${ }^{4}$ Department of Chemistry, Nanoscience Centre, University of Jyväskylä, P.O. Box 35, FI-40014 Jyväskylä, Finland. \\ *Corresponding author. Email: r.layfield@sussex.ac.uk
}

Single-molecule magnets (SMMs) containing only one metal center may represent the lower size limit for molecule-based magnetic information storage materials. Their current drawback is that all SMMs require liquid-helium cooling to show magnetic memory effects. We now report a chemical strategy to access the dysprosium metallocene cation $\left[\left(C p^{\text {Pr5 }}\right) D y\left(C p^{*}\right)\right]^{+}\left(C p^{\text {Pr5 }}=\right.$ penta-iso-propylcyclopentadienyl, $C p^{*}=$ pentamethylcyclopentadienyl), which displays magnetic hysteresis above liquid-nitrogen temperatures. An effective energy barrier to reversal of the magnetization of $U_{\text {eff }}=1,541 \mathrm{~cm}^{-1}$ is also measured. The magnetic blocking temperature of $T_{\mathrm{B}}=80 \mathrm{~K}$ for this cation overcomes an essential barrier towards the development of nanomagnet devices that function at practical temperatures.

The observation of slow magnetic relaxation in coordination compounds that contain a single lanthanide ion stimulated considerable interest in monometallic single-molecule magnets (SMMs) (1). This family of materials shows magnetic hysteresis properties that arise from the electronic structure at the molecular level rather than interactions across comparatively large magnetic domains (2-4). In addition to the considerable fundamental interest in SMMs and related magnetic molecules, their magnetic memory properties have inspired proposals for applications as spin qubits (5) and in nanoscale spintronic devices (6). A key performance parameter of an SMM is the magnetic blocking temperature, $T_{\mathrm{B}}$, one description of which refers the maximum temperature at which it is possible to observe hysteresis in the field-dependence of the magnetization, subject to the field sweep rate. The blocking temperature provides a means of comparing different SMMs and, to date, the vast majority that show any hysteresis at all require liquid-helium cooling to do so $(7,8)$. A few notable examples have emerged from the extreme cold to set record blocking temperatures above the liquid-helium regime (9-12), including the dysprosium metallocene $\left[\left(\mathrm{Cp}^{\mathrm{ttt}}\right)_{2} \mathrm{Dy}\right]\left[\mathrm{B}\left(\mathrm{C}_{6} \mathrm{~F}_{5}\right)_{4}\right]\left(\mathrm{Cp}^{\mathrm{ttt}}=1,2,4\right.$-tri-tert-butylcyclopentadienyl), which showed magnetic hysteresis with coercivity up to $60 \mathrm{~K}$ (13-15); however, this threshold still falls markedly short of the more practically accessible $77 \mathrm{~K}$ temperature at which nitrogen liquefies. We now show that by designing the ligand framework so that two key structural parameters - i.e., the Dy-Cp $\mathrm{p}_{\text {cent }}$ distances (cent refers to the centroid of the $\mathrm{Cp}$ ligand) and the Cp-Dy-Cp bending angle - are rendered short and wide, respectively, we achieve an axial crystal field of suf- ficient strength to furnish an SMM that shows hysteresis above $77 \mathrm{~K}$.

A dysprosium metallocene cation was targeted with cyclopentadienyl substituents of sufficient bulk to produce a wide Cp-Dy-Cp angle, but not too bulky to preclude close approach of the ligands. Thus, the borohydride precursor complex $\left[\left(\eta^{5}-\mathrm{Cp}^{i \mathrm{Pr} 5}\right) \mathrm{Dy}\left(\eta^{5}-\mathrm{Cp}^{*}\right)\left(\mathrm{BH}_{4}\right)\right](\mathbf{2})\left(\mathrm{Cp}^{i \mathrm{Pr} 5}=\right.$ penta-iso-propylcyclopentadienyl, $\mathrm{Cp}^{*}=$ pentamethylcyclopentadienyl $)$ was synthesized by treating $\left[\mathrm{Dy}\left(\eta^{5}-\mathrm{Cp}^{i \mathrm{Pr} 5}\right)\left(\mathrm{BH}_{4}\right)_{2}(\mathrm{THF})\right](\mathbf{1})$ with KCp* (Fig. 1). The molecular structures of $\mathbf{1}$ and $\mathbf{2}$ were determined by x-ray crystallography (tables S1 to S3 and figs. S4 and $\mathrm{S} 5)$. The target compound $\left[\left(\eta^{5}-\mathrm{Cp} *\right) \mathrm{Dy}\left(\eta^{5}\right.\right.$ $\left.\left.\mathrm{Cp}^{i \mathrm{Pr} 5}\right)\right]\left[\mathrm{B}\left(\mathrm{C}_{6} \mathrm{~F}_{5}\right)_{4}\right](3)$, hereafter abbreviated [Dy-5*] $\left.\mathrm{B}\left(\mathrm{C}_{6} \mathrm{~F}_{5}\right)_{4}\right]$, was then isolated in $60 \%$ yield by treating 2 with the superelectrophile $\left[\left(\mathrm{Et}_{3} \mathrm{Si}\right)_{2}(\mu-\mathrm{H}]\left[\mathrm{B}\left(\mathrm{C}_{6} \mathrm{~F}_{5}\right)_{4}\right]\right.$ (16). An x-ray crystallographic analysis of the molecular structure of 3 at $150 \mathrm{~K}$ (Fig. 1, figs. S6 and S7, and tables S1 and S4) revealed that the Dy$5^{*}$ cation features Dy-Cp* and Dy-Cp ${ }^{i \mathrm{Pr} 5}$ distances of 2.296(1) $\AA$ and 2.284(1) $\AA$, respectively, which are, on average, $0.026 \AA$ shorter than the analogous distances of $2.32380(8) \AA$ and $2.30923(8) \AA$ determined for $\left[\left(\mathrm{Cp}^{\mathrm{ttt}}\right)_{2} \mathrm{Dy}\right]^{+}$(13). Furthermore, the Cp-Dy-Cp angle in Dy-5* is $162.507(1)^{\circ}$, and hence almost $9.7^{\circ}$ wider than the angle of $152.845(2)^{\circ}$ found in $\left[\left(\mathrm{Cp}^{\mathrm{tt} t}\right)_{2} \mathrm{Dy}\right]^{+}$. Based on these structural parameters, the crystal field in Dy$5^{*}$ should be stronger and more axial than in $\left[\left(\mathrm{Cp}^{\mathrm{ttt}}\right)_{2} \mathrm{Dy}\right]^{+}$, and hence an improvement in the SMM properties can be expected.

The D.C. molar magnetic susceptibility $\left(\chi_{\mathrm{M}}\right)$ was measured for compounds 1-3 in the temperature range 2 to $300 \mathrm{~K}$ using an applied field of $1000 \mathrm{Oe}$, and the field-dependence of the 
magnetization for $\mathbf{1}$ and $\mathbf{2}$ was measured at $T=2$ and $5 \mathrm{~K}$ using fields up to $70 \mathrm{kOe}$ (figs. S8 to S12). A description of the properties of $\mathbf{1}$ and $\mathbf{2}$ is provided in the Supplementary Materials. For 3 , the $\chi_{\mathrm{M}} T$ value was measured to be $13.75 \mathrm{~cm}^{3} \mathrm{~K}$ $\mathrm{mol}^{-1}$ at $300 \mathrm{~K}$ and then manifested a steady decrease down to $75 \mathrm{~K}$. At lower temperatures a sharp drop in $\chi_{\mathrm{M}} T$ was observed, indicating the onset of magnetic blocking, with a value of $0.94 \mathrm{~cm}^{3} \mathrm{~K} \mathrm{~mol}{ }^{-1}$ reached at $2 \mathrm{~K}$. Overall, the D.C. magnetic properties of compounds 1-3 are typical for a monometallic complex of $\mathrm{Dy}^{3+}$ with a ${ }^{6} \mathrm{H}_{15 / 2}$ ground multiplet (17). The SMM properties of compounds 1-3 were then established through measurements of the in-phase (the real component, $\left.\chi^{\prime}\right)$ and the out-of-phase (the imaginary component, $\left.\chi^{\prime \prime}\right)$ A.C. susceptibilities as functions of the A.C. frequency ( $v$ ) and temperature, using an oscillating field of 5 Oe and zero applied D.C. field (figs. S13 to S28 and tables S5 to S7). Focusing again on 3, the $\chi^{\prime \prime}(v)$ isotherms show well-defined maxima up to 130 $\mathrm{K}$ (Fig. 2). The $\chi^{\prime}(v)$ and $\chi^{\prime \prime}(v)$ data were then used to derive Cole-Cole plots of $\chi^{\prime \prime}\left(\chi^{\prime}\right)$ for relaxation in the temperature range 82 to $138 \mathrm{~K}$ in intervals of $2 \mathrm{~K}$, with each plot adopting a parabolic shape (figs. S26 to S28,). Accurate fits of the A.C. susceptibility plots were obtained using equations describing $\chi^{\prime}$ and $\chi^{\prime \prime}$ in terms of frequency, the isothermal susceptibility $\left(\chi_{T}\right)$, adiabatic susceptibility $\left(\chi_{S}\right)$, the relaxation time $(\tau)$, and the fitting parameter $\alpha$ to represent the distribution of relaxation times (eq S1, S2) (18).

The resulting values of $\alpha=0$ to 0.027 indicate a very narrow range of relaxation times in the high-temperature regime. The relaxation times at temperatures in the range 2 to $83 \mathrm{~K}$ were determined in intervals of approximately $5 \mathrm{~K}$ from plots of the magnetization decay versus time (figs. S29 to S48 and table S8). These data show, for example, that the magnetization in $\mathbf{3}$ decays almost to zero over a 50-second time period at $77 \mathrm{~K}$, increasing to approximately 500 minutes at 15 $\mathrm{K}$. The temperature at which $\tau=100 \mathrm{~s}$ is $65 \mathrm{~K}$. The relaxation times determined from the A.C. and D.C. measurements were then combined to obtain further insight into the magnetic relaxation by plotting $\tau$ as a function of $T^{-1}$ (Fig. 2), which revealed a strong, linear dependence of the relaxation time on temperature in the range 55 to $138 \mathrm{~K}$. The $\tau\left(T^{-1}\right)$ plot in the range 10 to $55 \mathrm{~K}$ is curved in nature and represents an intermediate regime before purely temperature-independent relaxation is observed below $10 \mathrm{~K}$. The relaxation time can be expressed as $\tau^{-1}=\tau_{0}^{-1} e^{-U_{\text {eff }} / k_{\mathrm{B}} T}+C T^{n}+\tau_{Q T M}^{-1}$, in which the first term represents Orbach relaxation with $U_{\text {eff }}$ as the effective energy barrier to relaxation of the magnetization, the second term represents the contribution from Raman processes, and the third term represents the rate of quantum tunneling of the magnetization. Using this equation, an excellent fit (adjusted $\left.R^{2}=0.99958\right)$ of the data was obtained with $\tau_{0}=4.2(6)$ $\times 10^{-12} \mathrm{~s}, U_{\text {eff }}=1,541(11) \mathrm{cm}^{-1}, C=3.1(1) \times 10^{-8} \mathrm{~s}^{-1} \mathrm{~K}^{-n}$ and $n=$
$3.0(1)$, and $\tau_{\mathrm{QTM}}=2.5(2) \times 10^{4} \mathrm{~s}$. The $U_{\text {eff }}$ value determined for 3 exceeds the value of $1,277 \mathrm{~cm}^{-1}$ determined for $\left[\left(\mathrm{Cp}^{\mathrm{ttt}}\right)_{2} \mathrm{Dy}\right]\left[\mathrm{B}\left(\mathrm{C}_{6} \mathrm{~F}_{5}\right)_{4}\right]$ by approximately $20 \%$ (13).

Potential applications of SMMs in information storage devices rely on the occurrence of magnetic remanence and coercivity: therefore, the hysteresis is a critical consideration (19). For 3, using a relatively fast field sweep rate of 200 Oe $\mathrm{s}^{-1}$ revealed $M(H)$ hysteresis from $2 \mathrm{~K}$ up to $85 \mathrm{~K}$, with the loops gradually closing as the temperature increased (Fig. 3, $\mathrm{A}$ and $\mathrm{B})$. At these temperature limits, coercive fields of 50 kOe and 210 Oe (5.0 T and $21 \mathrm{mT})$, respectively, were measured (Fig. 3C, fig. S49, and table S9). Fixing the temperature at $77 \mathrm{~K}$, a reduction in the sweep rate resulted in the coercive field approximately halving with the rate, i.e., $H_{\mathrm{c}}=5,802$ Oe at $700 \mathrm{Oe} \mathrm{s}^{-1}, 2,946 \mathrm{Oe}$ at $350 \mathrm{Oe} \mathrm{s}^{-1}, 1,688 \mathrm{Oe}$ at $200 \mathrm{Oe} \mathrm{s}^{-1}$, $825 \mathrm{Oe}$ at $100 \mathrm{Oe} \mathrm{s}^{-1}, 398 \mathrm{Oe}$ at $50 \mathrm{Oe} \mathrm{s}^{-1}$ and $191 \mathrm{Oe}$ at $25 \mathrm{Oe}$ $\mathrm{s}^{-1}$ (fig. S50 and table S10). The observation of coercivity in $\mathbf{3}$ at $25 \mathrm{Oe} \mathrm{s}^{-1}$ is significant because this sweep rate is slower than the 39 Oe $\mathrm{s}^{-1}$ used to determine the blocking temperature of $60 \mathrm{~K}$ for $\left[\left(\mathrm{Cp}^{\mathrm{ttt}}\right)_{2} \mathrm{Dy}\right]\left[\mathrm{B}\left(\mathrm{C}_{6} \mathrm{~F}_{5}\right)_{4}\right](13)$. At $80 \mathrm{~K}$ and $25 \mathrm{Oe}$ $\mathrm{s}^{-1}$, a coercive field of 63 Oe was measured (Fig. 3D), and the loops were completely closed at higher temperatures. Consistent with this finding, the field-cooled and zero-fieldcooled magnetic susceptibilities for $\mathbf{3}$ diverged at $78 \mathrm{~K}$ (fig. $\mathrm{S} 51)$. By analogy with the development of high- $T_{\mathrm{C}}$ superconductors, we propose to designate the Dy-5* cation in 3 as a high-temperature, or high- $T_{\mathrm{B}}$, single-molecule magnet.

The importance of the strong axial crystal field in the Dy$5^{*}$ cation combined with the absence of an equatorial field is illustrated further by comparing the $U_{\text {eff }}$ and $T_{\mathrm{B}}$ values for $\mathbf{3}$ with those of the precursors $\mathbf{1}$ and $\mathbf{2}$. In the case of $\mathbf{1}$, the $\mathrm{Cp}^{i \operatorname{Pr} 5}$ ligand provides a strong axial field, but the pseudo-octahedral coordination geometry introduces a non-negligible equatorial field and, whilst slow magnetic relaxation in zero field is observed with this system, the position of the maxima in $\chi^{\prime \prime}(v)$ are temperature-independent up to $10 \mathrm{~K}$ and only observed up to $30 \mathrm{~K}$ (figs. S13 to S16). The resulting energy barrier of $241(7) \mathrm{cm}^{-1}$ is comparatively small, and the rate of quantum tunnelling of the magnetization (QTM) is, at 5.0(1) $\times 10^{-3} \mathrm{~s}$ (fig. S17), some seven orders of magnitude faster than found with $\mathbf{3}$. The competing equatorial field in $\mathbf{2}$ is more prominent as the maxima in $\chi^{\prime \prime}(v)$ are very weakly temperature-dependent from 3 to $20 \mathrm{~K}$, with the resulting energy barrier a negligible $7(1) \mathrm{cm}^{-1}$ (figs. S19 to S22). In both $\mathbf{1}$ and $\mathbf{2}$, the $M(H)$ hysteresis loops collected at $2 \mathrm{~K}$ and $200 \mathrm{Oe} \mathrm{s}^{-1}$ are waist-restricted, with no coercivity and only small openings as the field magnitude increases (figs. S18 and S23).

$A b$ initio calculations have enabled quantitative analysis of the properties of SMMs on a microscopic scale (20), particularly systems with $\eta^{n}$-bonded organometallic ligands (2130). Calculations on the Dy- $5^{*}$ cation were performed at the XMS-CASPT2//SA-CASSCF/RASSI level $(31,32)$ : the resulting 
energies, principal components of the $\boldsymbol{g}$-tensors and the principal magnetic axes of the eight lowest Kramers' doublets in Dy-5* corresponding to the CF-split states of the ${ }^{6} \mathrm{H}_{15 / 2}$ ground multiplet are listed in table S11. The principal magnetic axis in the ground doublet of Dy- $5^{*}$ (Fig. 4) is projected towards the centroids of the two cyclopentadienyl ligands, with the principal axes of the next six doublets almost collinear and the largest deviation angle $5.3^{\circ}$ with the fifth doublet. The highest doublet is perpendicular to the ground doublet.

The $\boldsymbol{g}$-tensor of the ground doublet is calculated to be perfectly axial, i.e., $g_{x}=\mathrm{g}_{\mathrm{y}}=0.000$ and $g_{z}=20.000$ (table S11), which is consistent with the experimental hysteresis measurements in which QTM is completely blocked at zero field. In the six lowest doublets, the CF is highly axial and each state can be assigned to a definite projection (greater than $96 \%$ character) of the total angular momentum, $M_{J}$ (table S12). The transverse components of the $\boldsymbol{g}$-tensors increase roughly by an order of magnitude in each doublet upon moving to higher energy. In the fifth doublet the transverse components start to become significant and in the sixth doublet the transverse components are large enough to allow considerable tunneling. In the two highest states, the axiality is weaker and considerable mixing occurs under the $\mathrm{CF}$, which most likely results from the asymmetry of the coordination environment.

The $a b$-initio CF parameters were calculated for the Dy-5* cation following a previously established methodology (33, 34) and are listed in table S13. The off-diagonal elements of the CF operator clearly have non-negligible elements due to the low $C_{1}$ point symmetry of Dy- $5^{*}$, however the axial secondrank parameter $B_{2}^{0}$ is at least two orders of magnitude larger than any other parameter. This creates a highly axial CF environment despite the absence of point symmetry (or pseudosymmetry) that would be needed for a strictly axial CF. The off-diagonal elements of the CF play some role and, in the higher-lying doublets of the ground multiplet, the axial nature of the $\mathrm{CF}$ is lost (vide infra). This demonstrates that strict point symmetry is not required to achieve a highly axial $\mathrm{CF}$, provided the axial parameters are sufficiently strong in comparison to the other CF parameters arising from the lowsymmetry components of the CF.

The magnetic relaxation in the Dy- $5^{*}$ cation was studied further by constructing a qualitative relaxation barrier from the $a b$ initio results, which follows a methodology in which the transition magnetic moment between the different states was calculated and the relaxation pathway follows the largest matrix elements (Fig. 4B and table S14) (35). The results predict that the barrier is crossed at the fourth excited doublet, corresponding to a $U_{\text {eff }}$ value of $1,524 \mathrm{~cm}^{-1}$ for the Orbach process, which is consistent with the calculated $\boldsymbol{g}$-tensors for this doublet and is in excellent agreement with the experimentally determined barrier height of $1,541(11) \mathrm{cm}^{-1}$. To gain deeper insight into the nature of the spin-phonon relaxation, the first-order spin-phonon couplings with the optical phonons (approximated as the molecular vibrations) were evaluated from first-principles calculations (tables S15-S18). In earlier work on $\left[\left(\mathrm{Cp}^{\mathrm{ttt}}\right)_{2} \mathrm{Dy}\right]^{+}(14)$, vibrations of the $\mathrm{C}-\mathrm{H}$ oscillators in the $\mathrm{Cp}$ rings were recognized as the most important contribution to the Orbach relaxation as they initiated the transition from the ground doublet to the first excited doublet. In the case of Dy- $5^{*}$, these oscillators are absent, and the analogous transition from the ground to the first excited doublet is most likely initiated by out-of-plane vibrations of the $\mathrm{Cp}^{*}$ ligand when comparing the frequency of these modes $\left(632.9 \mathrm{~cm}^{-1}\right.$ and $\left.640.5 \mathrm{~cm}^{-1}\right)$ to the calculated gap between the ground and first-excited doublets $\left(672 \mathrm{~cm}^{-1}\right)$ (see movies S1 to S7). Because the out-of-plane vibrations couple strongly to vibrations of the $\mathrm{Cp}^{*}$ methyl groups, it is conceivable that their energies can be tuned by choosing ligand substituents that would bring the vibrational modes out of resonance with the excitation gap. Such an approach should lead to further improvements in SMM performance beyond those of the Dy-5* cation, and therefore enhance their potential for applications in magnetic information storage materials.

\section{REFERENCES AND NOTES}

1. N. Ishikawa, M. Sugita, T. Ishikawa, S. Y. Koshihara, Y. Kaizu, Lanthanide doubledecker complexes functioning as magnets at the single-molecular level. J. Am. Chem. Soc. 125, 8694-8695 (2003). doi:10.1021/ja029629n Medline

2. B. M. Day, F.-S. Guo, R. A. Layfield, Cyclopentadienyl ligands in lanthanide singlemolecule magnets: One ring to rule them all? Acc. Chem. Res. 51, 1880-1889 (2018). doi:10.1021/acs.accounts.8b00270 Medline

3. J.-L. Liu, Y.-C. Chen, M.-L. Tong, Symmetry strategies for high performance lanthanide-based single-molecule magnets. Chem. Soc. Rev. 47, 2431-2453 (2018). doi:10.1039/C7CS00266A Medline

4. J. M. Frost, K. L. M. Harriman, M. Murugesu, The rise of 3-d single-ion magnets in molecular magnetism: Towards materials from molecules? Chem. Sci. 7, 24702491 (2016). doi:10.1039/C5SC03224E Medline

5. M. Shiddiq, D. Komijani, Y. Duan, A. Gaita-Ariño, E. Coronado, S. Hill, Enhancing coherence in molecular spin qubits via atomic clock transitions. Nature 531, 348351 (2016). doi:10.1038/nature16984 Medline

6. S. Thiele, F. Balestro, R. Ballou, S. Klyatskaya, M. Ruben, W. Wernsdorfer, Electrically driven nuclear spin resonance in single-molecule magnets. Science 344, 1135-1138 (2014). doi:10.1126/science.1249802 Medline

7. D. N. Woodruff, R. E. P. Winpenny, R. A. Layfield, Lanthanide single-molecule magnets. Chem. Rev. 113, 5110-5148 (2013). doi:10.1021/cr400018q Medline

8. P. Zhang, L. Zhang, J. Tang, Lanthanide single molecule magnets: Progress and perspective. Dalton Trans. 44, 3923-3929 (2015). doi:10.1039/C4DT03329A Medline

9. J. D. Rinehart, M. Fang, W. J. Evans, J. R. Long, A N $2^{3-}$ radical-bridged terbium complex exhibiting magnetic hysteresis at 14 K. J. Am. Chem. Soc. 133, 1423614239 (2011). doi:10.1021/ja206286h Medline

10. Y.-C. Chen, J.-L. Liu, L. Ungur, J. Liu, Q.-W. Li, L.-F. Wang, Z.-P. Ni, L. F. Chibotaru, X.-M. Chen, M.-L. Tong, Symmetry-supported magnetic blocking at $20 \mathrm{~K}$ in pentagonal bipyramidal Dy(III) single-ion magnets. J. Am. Chem. Soc. 138, 28292837 (2016). doi:10.1021/jacs.5b13584 Medline

11. S. K. Gupta, T. Rajeshkumar, G. Rajaraman, R. Murugavel, An air-stable Dy(III) single-ion magnet with high anisotropy barrier and blocking temperature. Chem. Sci. 7, 5181-5191 (2016). doi:10.1039/C6SC00279J Medline

12. F. Liu, D. S. Krylov, L. Spree, S. M. Avdoshenko, N. A. Samoylova, M. Rosenkranz, A. Kostanyan, T. Greber, A. U. B. Wolter, B. Büchner, A. A. Popov, Single molecule magnet with an unpaired electron trapped between two lanthanide ions inside a 
fullerene. Nat. Commun. 8, 16098 (2017). doi:10.1038/ncomms16098 Medline

13. F.-S. Guo, B. M. Day, Y.-C. Chen, M.-L. Tong, A. Mansikkamäki, R. A. Layfield, A dysprosium metallocene single-molecule magnet functioning at the axial limit. Angew. Chem. Int. Ed. 56, 11445-11449 (2017). doi:10.1002/anie.201705426 Medline

14. C. A. P. Goodwin, F. Ortu, D. Reta, N. F. Chilton, D. P. Mills, Molecular magnetic hysteresis at 60 kelvin in dysprosocenium. Nature 548, 439-442 (2017). doi:10.1038/nature23447 Medline

15. C. A. P. Goodwin, D. Reta, F. Ortu, N. F. Chilton, D. P. Mills, Synthesis and electronic structures of heavy lanthanide metallocenium cations. J. Am. Chem. Soc. 139, 18714-18724 (2017). doi:10.1021/jacs.7b11535 Medline

16. S. J. Connelly, W. Kaminsky, D. M. Heinekey, Structure and solution reactivity of (triethylsilylium)triethylsilane cations. Organometallics 32, 7478-7481 (2013). doi:10.1021/om400970j

17. C. Benelli, D. Gatteschi, Introduction to Molecular Magnetism: From Transition Metals to Lanthanides (Wiley-VCH, 2015).

18. Y.-N. Guo, G.-F. Xu, Y. Guo, J. Tang, Relaxation dynamics of dysprosium(III) single molecule magnets. Dalton Trans. 40, 9953-9963 (2011). doi:10.1039/c1dt10474h Medline

19. S. Demir, M. I. Gonzalez, L. E. Darago, W. J. Evans, J. R. Long, Giant coercivity and high magnetic blocking temperatures for $\mathrm{N}_{2}{ }^{3-}$ radical-bridged dilanthanide complexes upon ligand dissociation. Nat. Commun. 8, 2144 (2017). doi:10.1038/s41467-017-01553-w Medline

20. L. Ungur, L. F. Chibotaru, Strategies toward high-temperature lanthanide-based single-molecule magnets. Inorg. Chem. 55, $10043-10056$ (2016). doi:10.1021/acs.inorgchem.6b01353 Medline

21. L. Ungur, J. J. Le Roy, I. Korobkov, M. Murugesu, L. F. Chibotaru, Fine-tuning the local symmetry to attain record blocking temperature and magnetic remanence in a single-ion magnet. Angew. Chem. Int. Ed. 53, 4413-4417 (2014). doi:10.1002/anie.201310451 Medline

22. J. J. Le Roy, L. Ungur, I. Korobkov, L. F. Chibotaru, M. Murugesu, Coupling strategies to enhance single-molecule magnet properties of erbiumcyclooctatetraenyl complexes. J. Am. Chem. Soc. 136, 8003-8010 (2014). doi:10.1021/ja5022552 Medline

23. J. J. Le Roy, M. Jeletic, S. I. Gorelsky, I. Korobkov, L. Ungur, L. F. Chibotaru, M. Murugesu, An organometallic building block approach to produce a multidecker If single-molecule magnet. J. Am. Chem. Soc. 135, 3502-3510 (2013). doi:10.1021/ja310642h Medline

24. K. L. M. Harriman, J. J. Le Roy, L. Ungur, R. J. Holmberg, I. Korobkov, M. Murugesu, Cycloheptatrienyl trianion: An elusive bridge in the search of exchange coupled dinuclear organolanthanide single-molecule magnets. Chem. Sci. 8, 231-240 (2017). doi:10.1039/C6SC01224H Medline

25. T. P. Latendresse, N. S. Bhuvanesh, M. Nippe, Hard single-molecule magnet behavior by a linear trinuclear lanthanide-[1]metallocenophane complex. J. Am. Chem. Soc. 139, 14877-14880 (2017). doi:10.1021/jacs.7b08690 Medline

26. T. Pugh, N. F. Chilton, R. A. Layfield, A low-symmetry dysprosium metallocene single-molecule magnet with a high anisotropy barrier. Angew. Chem. Int. Ed. 55 , 11082-11085 (2016). doi:10.1002/anie.201604346 Medline

27. T. Pugh, F. Tuna, L. Ungur, D. Collison, E. J. L. McInnes, L. F. Chibotaru, R. A. Layfield, Influencing the properties of dysprosium single-molecule magnets with phosphorus donor ligands. Nat. Commun. 6, 7492 (2015). doi:10.1038/ncomms8492 Medline

28. T. Pugh, V. Vieru, L. F. Chibotaru, R. A. Layfield, Magneto-structural correlations in arsenic- and selenium-ligated dysprosium single-molecule magnets. Chem. Sci. 7, 2128-2137 (2016). doi:10.1039/C5SC03755G Medline

29. T. Pugh, N. F. Chilton, R. A. Layfield, Antimony-ligated dysprosium single-molecule magnets as catalysts for stibine dehydrocoupling. Chem. Sci. 8, 2073-2080 (2017). doi:10.1039/C6SC04465D Medline

30. A. F. R. Kilpatrick, F.-S. Guo, B. M. Day, A. Mansikkamäki, R. A. Layfield, F. G. N. Cloke, Single-molecule magnet properties of a monometallic dysprosium pentalene complex. Chem. Commun. (Camb.) 54, 7085-7088 (2018). doi:10.1039/C8CC03516D Medline

31. L. Ungur, L. F. Chibotaru, Computational Modelling of Magnetic Properties of Lanthanide Compounds in Lanthanide and Actinides in Molecular Magnetism, R. A. Layfield, M. Murugesu, Eds. (Wiley-VCH, 2015).
32. T. Shiozaki, W. Gyõrffy, P. Celani, H.-J. Werner, Communication: extended multistate complete active space second-order perturbation theory: energy and nuclear gradients. J. Chem. Phys. 135, 081106 (2011). doi:10.1063/1.3633329 Medline

33. L. Ungur, L. F. Chibotaru, Ab initio crystal field for lanthanides. Chemistry 23 , 3708-3718 (2017). doi:10.1002/chem.201605102 Medline

34. L. F. Chibotaru, in Ab Initio Methodology for Pseudospin Hamiltonians of Anisotropic Magnetic Complexes, S. A. Rice, A. R. Dinner, Eds. (Advances in Chemical Physics Series, Wiley, 2013), vol. 153, pp. 397-519.

35. L. Ungur, M. Thewissen, J.-P. Costes, W. Wernsdorfer, L. F. Chibotaru, Interplay of strongly anisotropic metal ions in magnetic blocking of complexes. Inorg. Chem. 52, 6328-6337 (2013). doi:10.1021/ic302568x Medline

36. H. Sitzmann, Synthese von 1,2,3,4,5-Pentaisopropylcyclopentadien und 1,3,5-Tritert-butylcyclopentadien / Synthesis of 1,2,3,4,5-Pentaisopropylcyclopentadiene and 1,3,5-Tri-tert-butylcyclopentadiene. Z. Naturforsch B 44, 1293-1297 (1989). doi:10.1515/znb-1989-1025

37. S. M. Cendrowski-Guillaume, G. Le Gland, M. Nierlich, M. Ephritikhine, Lanthanide borohydrides as precursors to organometallic compounds. mono(cyclooctatetraenyl) neodymium complexes. Organometallics 19, 56545660 (2000). doi:10.1021/om000558f

38. W. J. Evans, S. A. Kozimor, J. W. Ziller, N. Kaltsoyannis, Structure, reactivity, and density functional theory analysis of the six-electron reductant, $\left[\left(\mathrm{C}_{5} \mathrm{Me}_{5}\right)_{2} \mathrm{U}\right]_{2}(\mu-$ $\left.\eta^{6}: \eta^{6}-\mathrm{C}_{6} \mathrm{H}_{6}\right)$, synthesized via a new mode of $\left(\mathrm{C}_{5} \mathrm{Me}_{5}\right)_{3} \mathrm{M}$ reactivity. J. Am. Chem. Soc. 126, 14533-14547 (2004). doi:10.1021/ja0463886 Medline

39. O. V. Dolomanov, L. J. Bourhis, R. J. Gildea, J. A. K. Howard, H. Puschmann, OLEX2: A complete structure solution, refinement and analysis program. J. Appl. Cryst. 42, 339-341 (2009). doi:10.1107/S0021889808042726

40. G. M. Sheldrick, SHELXT-Integrated space-group and crystal-structure determination. Acta Crystallogr. A Found Adv. 71, 3-8 (2015). doi:10.1107/S2053273314026370 Medline

41. G. M. Sheldrick, Crystal structure refinement with SHELXL. Acta Crystallogr. C Struct. Chem. 71, 3-8 (2015). doi:10.1107/S2053229614024218 Medline

42. G. A. Bain, J. F. Berry, Diamagnetic corrections and Pascal's constants. J. Chem. Educ. 85, 532 (2008). doi:10.1021/ed085p532

43. D. Gatteschi, R. Sessoli, J. Villain, Molecular Nanomagnets (Oxford Univ. Press, 2006).

44. D. Gatteschi, R. Sessoli, Quantum tunneling of magnetization and related phenomena in molecular materials. Angew. Chem. Int. Ed. 42, 268-297 (2003). doi:10.1002/anie.200390099 Medline

45. F. Aquilante, J. Autschbach, R. K. Carlson, L. F. Chibotaru, M. G. Delcey, L. De Vico, I. Fdez Galván, N. Ferré, L. M. Frutos, L. Gagliardi, M. Garavelli, A. Giussani, C. E. Hoyer, G. Li Manni, H. Lischka, D. Ma, P. A. Malmqvist, T. Müller, A. Nenov, M. Olivucci, T. B. Pedersen, D. Peng, F. Plasser, B. Pritchard, M. Reiher, I. Rivalta, I. Schapiro, J. Segarra-Martí, M. Stenrup, D. G. Truhlar, L. Ungur, A. Valentini, S. Vancoillie, V. Veryazov, V. P. Vysotskiy, O. Weingart, F. Zapata, R. Lindh, Molcas 8: New capabilities for multiconfigurational quantum chemical calculations across the periodic table. J. Comput. Chem. 37, 506-541 (2016). doi:10.1002/jcc.24221 Medline

46. P.-O. Widmark, P.-Å. Malmqvist, B. O. Roos, Density matrix averaged atomic natural orbital (ANO) basis sets for correlated molecular wave functions. Theor Chim. Acta 77, 291-306 (1990). doi:10.1007/BF01120130

47. B. O. Roos, R. Lindh, P. A.. Malmqvist, V. Veryazov, P.-O. Widmark, Main group atoms and dimers studied with a new relativistic ANO basis set. J. Phys. Chem. A 108, 2851-2858 (2004). doi:10.1021/jp031064+

48. W. Kutzelnigg, W. Liu, Quasirelativistic theory equivalent to fully relativistic theory. J. Chem. Phys. 123, 241102 (2005). doi:10.1063/1.2137315 Medline

49. M. Filatov, Comment on "Quasirelativistic theory equivalent to fully relativistic theory" [J. Chem. Phys. 123, 241102 (2005)]. J. Chem. Phys. 125, 107101 (2006) doi:10.1063/1.2338033 Medline

50. D. Peng, M. Reiher, Exact decoupling of the relativistic Fock operator. Theor Chem. Acc. 131, 1081 (2012). doi:10.1007/s00214-011-1081-y

51. B. O. Roos, in Ab Initio Methods in Quantum Chemistry, Part II, K. P. Lawley, Ed. (Advances in Chemical Physics Series, Wiley, 1987), vol. 69, pp. 399-455.

52. P. Siegbahn, A. Heiberg, B. Roos, B. Levy, A comparison of the super- $\mathrm{Cl}$ and the Newton-Raphson scheme in the complete active space SCF method. Phys. Scr. 21, 
323-327 (1980). doi:10.1088/0031-8949/21/3-4/014

53. B. O. Roos, P. R. Taylor, P. E. M. Sigbahn, A complete active space SCF method (CASSCF) using a density matrix formulated super-Cl approach. Chem. Phys. 48 , 157-173 (1980). doi:10.1016/0301-0104(80)80045-0

54. P. E. M. Siegbahn, J. Almlöf, A. Heiberg, B. Roos, The complete active space SCF (CASSCF) method in a Newton-Raphson formulation with application to the HNO molecule. J. Chem. Phys. 74, 2384-2396 (1981). doi:10.1063/1.441359

55. B. O. Roos, R. Lindh, P. A. Malmqvist, V. Veryazov, P.-0. Widmark, Multiconfigurational Quantum Chemistry (Wiley, 2016).

56. B. O. Roos, P. Linse, P. E. M. Siegbahn, M. R. A. Blomberg, A simple method for the evaluation of the second-order-perturbation energy from external doubleexcitations with a CASSCF reference wavefunction. Chem. Phys. 66, 197-207 (1982). doi:10.1016/0301-0104(82)88019-1

57. K. Andersson, P. A. Malmqvist, B. O. Roos, A. J. Sadlej, K. Wolinski, Second-order perturbation theory with a CASSCF reference function. J. Phys. Chem. 94, 54835488 (1990). doi:10.1021/i100377a012

58. K. Andersson, P.-A. Malmqvist, B. O. Roos, Second-order perturbation theory with a complete active space self-consistent field reference function. J. Chem. Phys. 96, 1218-1226 (1992). doi:10.1063/1.462209

59. P. A. Malmqvist, B. O. Roos, B. Schimmelpfennig, The restricted active space (RAS) state interaction approach with spin-orbit coupling. Chem. Phys. Lett. 357, 230-240 (2002). doi:10.1016/S0009-2614(02)00498-0

60. L. F. Chibotaru, L. Ungur, Ab initio calculation of anisotropic magnetic properties of complexes. I. Unique definition of pseudospin Hamiltonians and their derivation. J. Chem. Phys. 137, 064112 (2012). doi:10.1063/1.4739763 Medline

61. M. J. Frisch, G. W. Trucks, H. B. Schlegel, G. E. Scuseria, M. A. Robb, J. R. Cheeseman, G. Scalmani, V. Barone, G. A. Petersson, H. Nakatsuji, X. Li, M. Caricato, A. Marenich, J. Bloino, B. G. Janesko, R. Gomperts, B. Mennucci, H. P. Hratchian, J. V. Ortiz, A. F. Izmaylov, J. L. Sonnenberg, D. Williams-Young, F. Ding, F. Lipparini, F. Egidi, J. Goings, B. Peng, A. Petrone, T. Henderson, D. Ranasinghe, V. G. Zakrzewski, J. Gao, N. Rega, G. Zheng, W. Liang, M. Hada, M. Ehara, K. Toyota, R. Fukuda, J. Hasegawa, M. Ishida, T. Nakajima, Y. Honda, O. Kitao, H. Nakai, T. Vreven, K. Throssell, J. A. Montgomery J.., J. E. Peralta, F. Ogliaro, M. Bearpark, J. J. Heyd, E. Brothers, K. N. Kudin, V. N. Staroverov, T. Keith, R. Kobayashi, J. Normand, K. Raghavachari, A. Rendell, J. C. Burant, S. S. Iyengar, J. Tomasi, M. Cossi, J. M. Millam, M. Klene, C. Adamo, R. Cammi, J. W. Ochterski, R. L. Martin, K. Morokuma, O. Farkas, J. B. Foresman, D. J. Fox, Gaussian 09, Revision D.01 (Gaussian, Inc., Wallingford, CT, 2009).

62. J. P. Perdew, K. Burke, M. Ernzerhof, Generalized gradient approximation made simple. Phys. Rev. Lett. 77, 3865-3868 (1996). doi:10.1103/PhysRevLett.77.3865 Medline

63. J. P. Perdew, K. Burke, M. Ernzerhof, Generalized gradient approximation made simple [Phys. Rev. Lett. 77, 3865 (1996)]. Phys. Rev. Lett. 78, 1396 (1997). doi:10.1103/PhysRevLett.78.1396

64. M. Ernzerhof, G. E. Scuseria, Assessment of the Perdew-Burke-Ernzerhof exchange-correlation functional. J. Chem. Phys. 110, 5029-5036 (1999). doi:10.1063/1.478401

65. C. Adamo, V. Barone, Toward reliable density functional methods without adjustable parameters: The PBE0 model. J. Chem. Phys. 110, 6158-6170 (1999). doi:10.1063/1.478522

66. A. Schäfer, C. Huber, R. Ahlrichs, Fully optimized contracted Gaussian basis sets of triple zeta valence quality for atoms Li to Kr. J. Chem. Phys. 100, 5829-5835 (1994). doi:10.1063/1.467146

67. M. Dolg, H. Stoll, A. Savin, H. Preuss, Energy-adjusted pseudopotentials for the rare earth elements. Theor. Chim. Acta 75, 173-194 (1989). doi:10.1007/BF00528565

68. M. Dolg, H. Stoll, H. Preuss, A combination of quasirelativistic pseudopotential and ligand field calculations for lanthanoid compounds. Theor. Chim. Acta 85, 441450 (1993). doi:10.1007/BF01112983

69. J. Yang, M. Dolg, Valence basis sets for lanthanide 4f-in-core pseudopotentials adapted for crystal orbital ab initio calculations. Theor. Chem. Acc. 113, 212-224 (2005). doi:10.1007/s00214-005-0629-0

70. A. Weigand, X. Cao, J. Yang, M. Dolg, Quasirelativistic f-in-core pseudopotentials and core-polarization potentials for trivalent actinides and lanthanides: Molecular test for trifluorides. Theor. Chem. Acc. 126, 117-127 (2010). doi:10.1007/s00214-
009-0584-2

71. S. Grimme, J. Antony, S. Ehrlich, H. Krieg, A consistent and accurate ab initio parametrization of density functional dispersion correction (DFT-D) for the 94 elements H-Pu. J. Chem. Phys. 132, 154104 (2010). doi:10.1063/1.3382344 Medline

72. S. Grimme, S. Ehrlich, L. Goerigk, Effect of the damping function in dispersion corrected density functional theory. J. Comput. Chem. 32, 1456-1465 (2011). doi:10.1002/jcc.21759 Medline

73. N. Iwahara, L. F. Chibotaru, Exchange interaction between J multiplets. Phys. Rev. B 91, 174438 (2015). doi:10.1103/PhysRevB.91.174438

74. N. Iwahara, L. Ungur, L. F. Chibotaru, J口-pseudospin states and the crystal field of cubic systems. Phys. Rev. B 98, 054436 (2018). doi:10.1103/PhysRevB.98.054436

75. K. N. Shrivastava, Theory of spin-lattice relaxation. Phys. Status Solidi, B Basic Res. 117, 437-458 (1983). doi:10.1002/pssb.2221170202

76. D. H. Moseley, S. E. Stavretis, K. Thirunavukkuarasu, M. Ozerov, Y. Cheng, L. L. Daemen, J. Ludwig, Z. Lu, D. Smirnov, C. M. Brown, A. Pandey, A. J. RamirezCuesta, A. C. Lamb, M. Atanasov, E. Bill, F. Neese, Z.-L. Xue, Spin-phonon couplings in transition metal complexes with slow magnetic relaxation. Nat. Commun. 9, 2572 (2018). doi:10.1038/s41467-018-04896-0 Medline

\section{ACKNOWLEDGMENTS}

The authors thank the CSC-IT Center for Science in Finland, the Finnish Grid and Cloud Infrastructure (persistent identifier urn:nbn:fi:research-infras2016072533), and Prof. H. M. Tuononen (University of Jyväskylä) for providing computational resources. Funding: The authors thank the European Research Council (CoG grant 646740), the EPSRC (EP/M022064/1), the NSF China (projects 21620102002, 91422302), the National Key Research and Development Program of China (2018YFA0306001) and the Academy of Finland (projects 282499, 289172). Author contributions: R.A.L. conceived the original idea and formulated the research aims. Synthetic and crystallographic work was carried out by F.-S.G. and B.M.D. Magnetic measurements were conducted by Y.C.C. and M.-L.T. The theoretical analysis was carried out by A.M. All authors analyzed the data. R.A.L. wrote the manuscript, with contributions from all authors. Competing interests: The authors declare no competing interests. Data and materials availability: Metrical data for the solid-state structures of 13 are available free of charge from the Cambridge Crystallographic Data Centre under reference numbers CCDC 1854466-1854468. All other data are in the main text or supplementary materials.

\section{SUPPLEMENTARY MATERIALS}

www.sciencemag.org/cgi/content/full/science.aav0652/DC1

Materials and Methods

Figs. S1 to S51

Tables S1 to S18

References (36-76)

Movies S1 to S7

Data S1 to S3

13 August 2018; accepted 9 October 2018

Published online 18 October 2018

10.1126/science.aav0652 


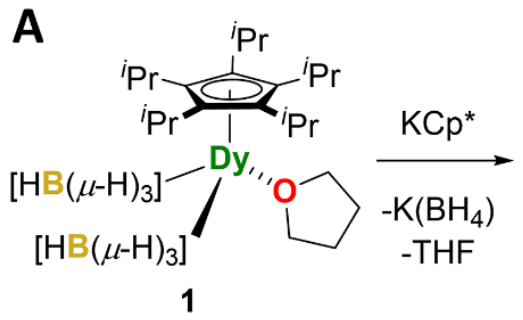

1
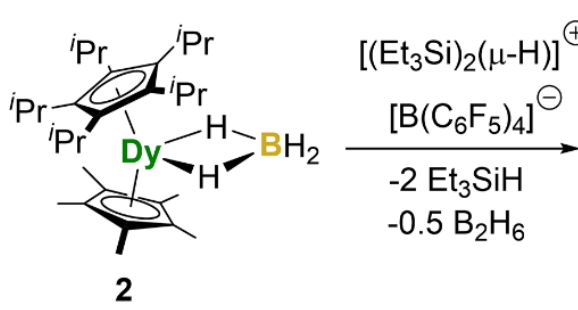

${ }_{3}^{\oplus}$

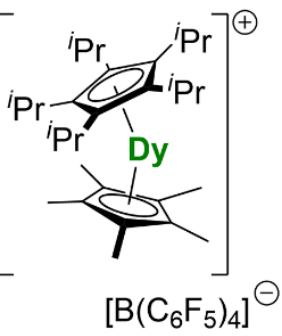

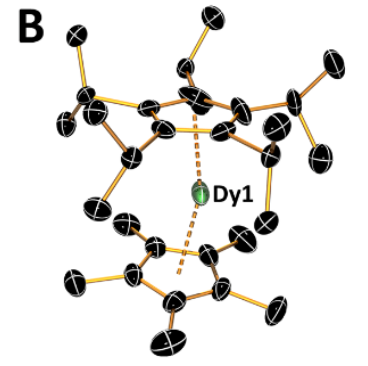

Fig. 1. Synthesis and molecular structures. (A) Reaction scheme for the synthesis of 3. $\mathrm{Cp}^{*}=$ pentamethylcyclopentadienyl. (B) Thermal ellipsoid representation (50\% probability) of the molecular structure of the Dy- $5^{*}$ cation in 3 , as determined by $x$-ray crystallography (for clarity, the hydrogen atoms and $\left[\mathrm{B}\left(\mathrm{C}_{6} \mathrm{~F}_{5}\right)_{4}\right]^{-}$counter anion are omitted).
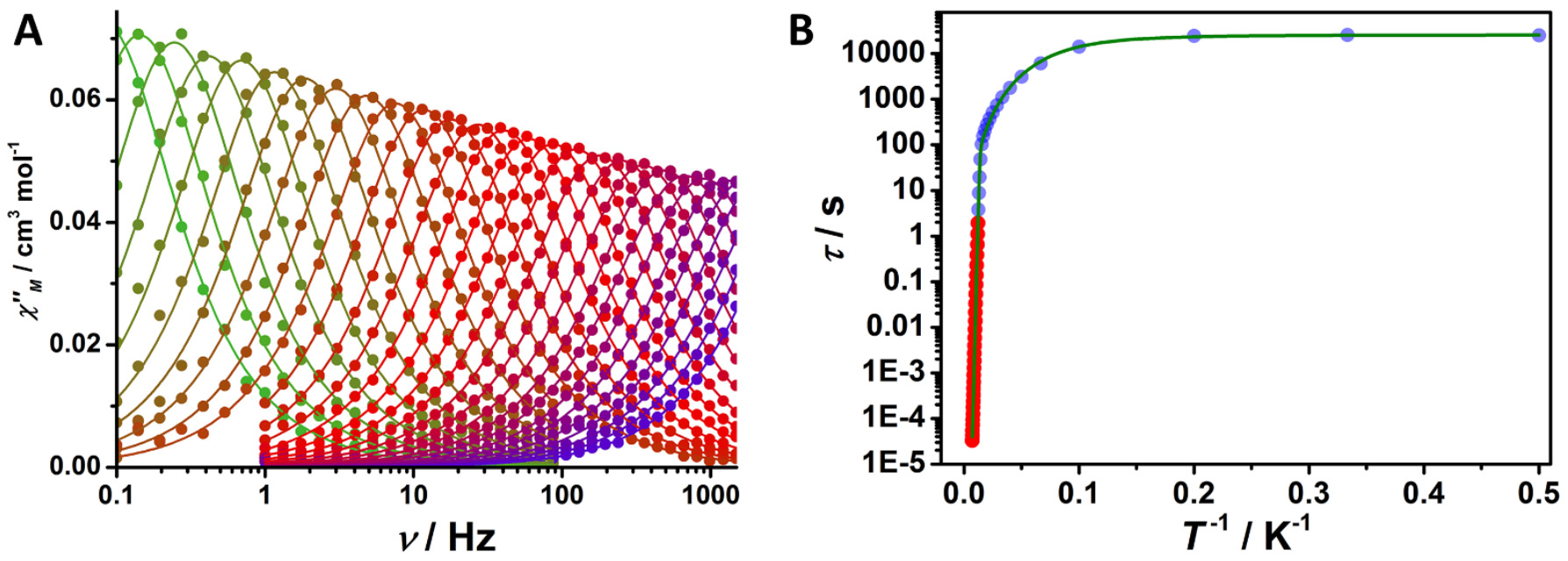

Fig. 2. Dynamic magnetic properties. (A) Frequency dependence of the out-of-phase $\chi^{\prime \prime} \mathrm{M}$ molar magnetic susceptibility for 3, collected in zero D.C. field at A.C. frequencies of $v=0.1$ to $1488 \mathrm{~Hz}$ from $82 \mathrm{~K}$ (green trace) to $138 \mathrm{~K}$ (purple trace) in $2 \mathrm{~K}$ intervals. Solid lines represent fits to the data using equations $S 1$ and $S 2$, with adjusted $R^{2}=0.99823-0.99988$. (B) Temperature dependence of the relaxation time for 3 . The red points are from the A.C. susceptibility data and the blue points are from measurements of the D.C. magnetic relaxation time. The solid green line is the best fit to $\tau^{-1}=\tau_{0}^{-1} e^{-U_{\text {eff }} / k_{\mathrm{B}} T}+C T^{n}+\tau_{Q T M}^{-1}$, using the parameters stated in the text. 

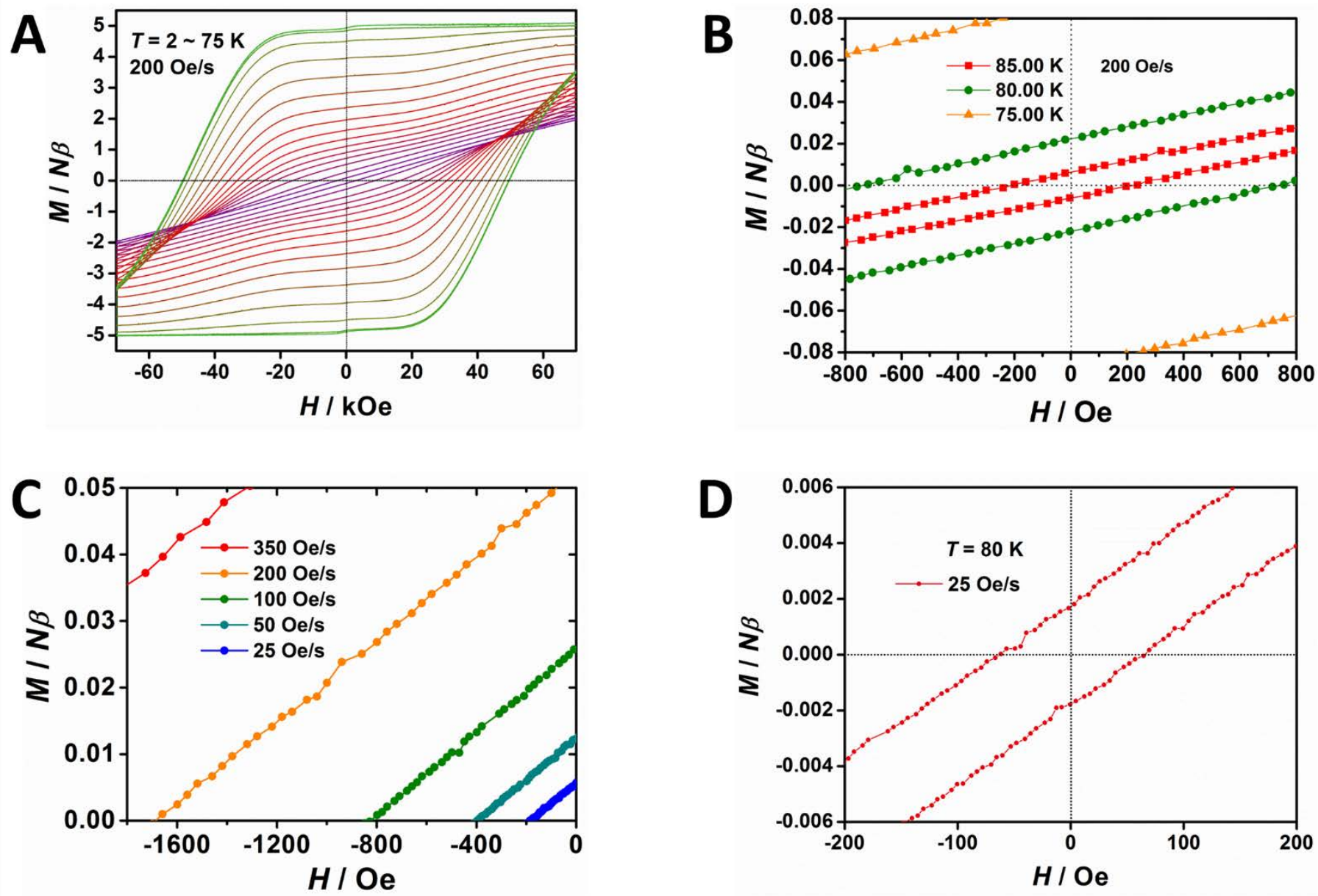

Fig. 3. Magnetic hysteresis properties of 3. (A and B) Magnetization vs. field hysteresis loops in the temperature ranges of 2 to $75 \mathrm{~K}(\mathrm{~A})$ and 75 to $85 \mathrm{~K}(\mathrm{~B})$ using a field sweep rate of $200 \mathrm{Oe} \mathrm{s}^{-1}$. (C) Expansion of the hysteresis loops at $77 \mathrm{~K}$ showing the coercive fields. (D) Hysteresis loops at $80 \mathrm{~K}$ using a field sweep rate of $25 \mathrm{Oe} \mathrm{s}^{-1}$. 

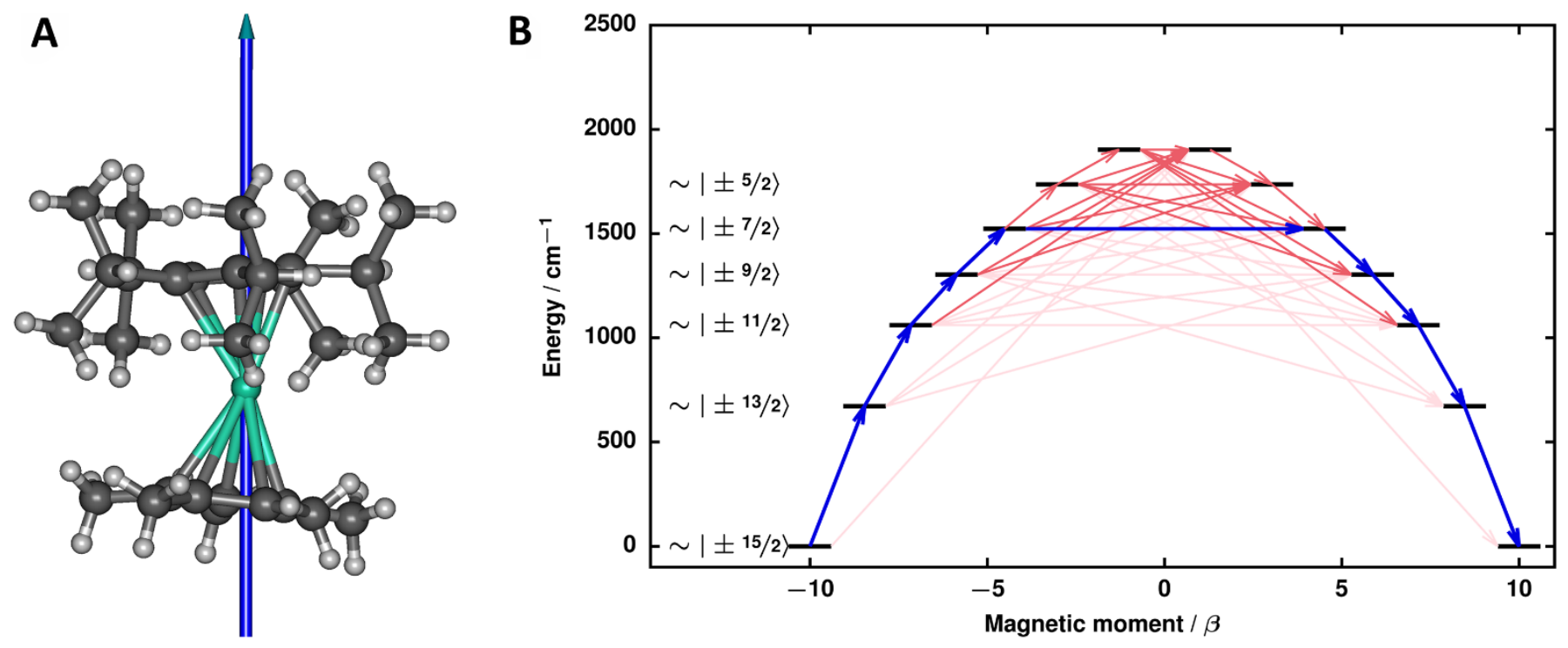

Fig. 4. Magnetic relaxation in the Dy-5* cation. (A) The principal magnetic axis of the ground Kramers' doublet. (B) Relaxation mechanism for Dy-5*. Blue arrows show the most probable relaxation route and red arrows show transitions between states with less probable but non-negligible matrix elements: darker shading indicates a higher probability. 